\title{
Pengaruh budaya organisasi dan komunikasi interpersonal terhadap kinerja pegawai di biro umum kementerian pendidikan dan kebudayaan republik indonesia \\ (Influence of interpersonal organizational culture and communication to employees performance in general bureau of the ministry of education and culture of the republic of indonesia)
}

\author{
Farouk Aziz', Edi Suryadi ${ }^{*}$ \\ ${ }^{1,2}$ Program Studi Pendidikan Manajemen Perkantoran, \\ Fakultas Pendidikan Ekonomi dan Bisnis, Universitas Pendidikan Indonesia, \\ JI. Dr. Setiabudhi No. 229 Bandung 40I32, lawa Barat, Indonesia \\ Email : edi_suryadi@upi.edu
}

\begin{abstract}
ABSTRAK
Penelitian ini berjudul "Pengaruh Budaya Organisasi dan Komunikasi Interpersonal Terhadap Kinerja Pegawai", yang bertujuan untuk mengetahui pengaruh budaya organisasi dan komunikasi komunikasi interpersonal terhadap kinerja pegawai. Metode yang digunakan adalah metode survey. Responden dari penelitian ini adalah para pegawai di Biro Umum Kementerian Pendidikan dan Kebudayaan Republik Indonesia. Teknik pengumpulan data menggunakan angket/kuisoner dengan rentang skor 1 sampai 5. Analisis data menggunakan kolerasi dan regresi. Hasil dari penelitian menunjukkan budaya organisasi dan komunikasi interpersonal berpengaruh positif terhadap kinerja pegawai. Maka dari itu, kinerja para pegawai dapat ditingkatkan dengan memperkuat budaya organisasi dan mengefektifkan komunikasi antar pribadi.
\end{abstract}

\begin{abstract}
This study entitled "The Influence of Organizational Culture and Interpersonal Communication on Employee Performance", which aims to determine the influence of organizational culture and communication communication interpersonal to employee performance. The method used is survey method. Respondents from this study were employees at the General Bureau of the Ministry of Education and Culture of the Republic of Indonesia. Technique of collecting data using questionnaire / kuisoner with score range 1 to 5. Analysis of data using correlation and regression. The results of the study show that organizational culture and interpersonal communication have a positive effect on employee performance. Therefore, the performance of employees can be enhanced by strengthening the organizational culture and streamlining interpersonal communication.
\end{abstract}

\section{PENDAHULUAN}

Memasuki era global saat ini seluruh negara-negara di seluruh dunia mendapati masalah yang semakin banyak serta solusi yang harus digunakannya yang bervariasi, terutama pada dunia kerja saat ini. Persaingan global dalam dunia kerja terutama pada organisasi-organisasi saat ini harus mampu bersaing dengan memperhatikan sumber daya manusia yang berkompeten. Organisasi-organisasi di Indonesia semakin selektif merekrut

\footnotetext{
* Corresponding author
}

Copyright (@ 2017, EISSN 2656-4734 
para pegawai u ntuk memperoleh hasil yang optimal, sumber daya yang kompeten dipilih agar dapat bersaing maupun bekerja dengan baik dan benar. Kinerja pegawai menjadi hal yang dapat mempengaruhi seberapa besar tercapainya target suatu organisasi. Masalah yang timbul di Kementerian Pendidikan dan Kebudayaan Republik Indonesia salah satunya ada pada kinerja pegawainya. Masalah ini tidak lepas dari kurangnya perhatian terhadap faktor yang menghambat pada kinerja para pegawainya. Adapun yang dikatakan oleh Bapak Drs. Gunawan Susanto sebagaimana hasil wawancara penulis bahwa: "Persoalan perihal penilaian prestasi kerja masih menjadi masalah yang ada di Kemdikbud, sebagaimana masih ada saja pegawai yang menginginkan nilai yang besar atas apa yang mereka kerjakan terutama pada saat penilaian masih DP3 (Daftar Penilaian Pelaksanaan Pekerjaan) Pegawai negeri sipil. Namun tahun lalu (2015) sistem penilaian kinerja pegawai diganti dari DP3 menjadi SKP (Sasaran Kinerja Pegawai) yang mana penilaian diambil dari hasil kerja mereka, mencakup beberapa aspek diantaranya kualitas kerja, kuantitas kerja, waktu, dan biaya yang dihasilkan oleh pegawai tersebut."

Berdasarkan data Prestasi Kerja Pegawai di Biro Umum Kementerian Pendidikan dan Kebudayaan Republik Indonesia.

Table 1

Data Prestasi Pegawai di Biro Umum Kementerian Pendidikan dan Kebudayaan Republik Indonesia Tahun 2013 sampai 2015

\begin{tabular}{|c|c|c|c|c|}
\hline \multirow{2}{*}{ No } & Unit Organisasi & \multicolumn{3}{|c|}{ Nilai } \\
\cline { 3 - 5 } & & $\mathbf{2 0 1 3}$ & $\mathbf{2 0 1 4}$ & $\mathbf{2 0 1 5}$ \\
\hline 1. & Biro Umum & 86,68 & 89,25 & 85,25 \\
\hline 2. & Bagian Keuangan dan Gaji & 86,72 & 87,56 & 84,10 \\
\hline 3. & Bagian Tata Usaha & 86,49 & 90,14 & 87,13 \\
\hline 4. & Bagian Barang Milik Negara & 87,36 & 90,14 & 83,59 \\
\hline 5. & $\begin{array}{c}\text { Bagian Rumah Tangga dan } \\
\text { Protokol }\end{array}$ & 85,98 & 87,36 & 86,34 \\
\hline
\end{tabular}

Sumber: DataPrestasi Kerja Biro Umum Kementerian Pendidikan dan Kebudayaan Republik Indonesias yang telah diinputpenulis.

Dari data tabel diatas dapat disimpulkan terjadi kenaikan nilai pada DP3 tahun 2014, kenaikan rata-rata berkisar sekitar 2 poin. Kenaikan paling signifikan terdapat pada bagian Tata Usaha yaitu 4 poin dengan perolehan nilai 86,49-90,14. Sedangkan kenaikan paling rendah terdapat pada bagian Keuangan dan Gaji yaitu 1 poin dengan perolehan nilai 86,7287,56 .

Setelah dianalisis, terdapat perbedaan form SKP dan DP3 mengenai pekerjaan yang harus dikerjakan oleh para pegawai. Dari keseluruhan empat bagian dalam Biro Umum penurunan rata-rata berkisar pada angka 3 poin. Bagian yang paling tinggi angka penurunannya adalah pada bagian Barang Milik Negara dengan poin 7 dengan perolehan nilai $90,14-83,59$.

Berdasarkan data di atas memperlihatkan bahwa kinerja yang diperlihatkan sesuai dengan standar kinerja pegawai yang harus naik dari tahun ketahunnya sudah terlaksana namun pada tahun 2015, penilaian prestasi kerja dirubah sistemnya menjadi SKP (Sasaran Kinerja Pegawai) yang mana penilaian lebih dipusatkan kepada pekerjaan yang dikerjakan sesuai form SKP yang diberikan oleh pimpinan terhadap pegawai. Maka dari itu masih belum dikatakan sesuai dengan harapan standar yang ada pada prestasi kerja yang di buat oleh Badan Kepegawaian Nasional sebagaimana tabel dibawah ini. 
Table 2

Standar Nilai Prestasi Kerja

\begin{tabular}{|c|l|}
\hline Kriteria Nilai & \multicolumn{1}{|c|}{ Keterangan } \\
\hline $91-100$ & $\begin{array}{l}\text { Hasil kerja sempurna tidak ada kesalahan, tidak ada revisi dan } \\
\text { pelayanan di atas standar yang ditentukan dan lain-lain. }\end{array}$ \\
\hline $76-90$ & $\begin{array}{l}\text { Hasil kerja mempunyai 1 (satu) atau 2 (dua) kesalahan kecil, tidak ada } \\
\text { kesalahan besasr, revisi, dan pelayanan sesuai dengan standar yang } \\
\text { telah ditentukan dan lain-lain. }\end{array}$ \\
\hline $61-75$ & $\begin{array}{l}\text { Hasil kerja mempunyai 3 (tiga) atau 4 (empat) kesalahan kecil, dan } \\
\text { tidak ada kesalahan besar, revisi dan pelayanan cukup memenuhi } \\
\text { standar yang ditentukan, dan lain-lain. }\end{array}$ \\
\hline $51-60$ & $\begin{array}{l}\text { Hasil kerja mempunyai 5 (lima) kesalahan kecil dan ada kesalahan } \\
\text { besar, revisi dan pelayanan tidak cukup memenuhi standar yang } \\
\text { ditentukan dan lain-lain. }\end{array}$ \\
\hline 50 ke bawah & $\begin{array}{l}\text { Hasil kerja mempunyai lebih dari 5 (lima) kesalahan kecil dan ada } \\
\text { kesalahan besar, kurang memuaskan, revisi, pelayanan di bawah } \\
\text { standar yang ditentukan dan lain-lain. }\end{array}$ \\
\hline
\end{tabular}

Sumber: Badan Kepegawaian Nasional

Dilihat dari masing-masing nilai yang diperoleh subbagian dalam masing-masing bagian setelah diberlakukannya sistem SKP, maka dapat ditarik kesimpulan secara keseluruhan pegawai pada masing-masing hanya melakukan 1 sampai 2 kesalahan, jenis kesalahannya ringan, tidak revisi dan pelayanan yang diberikan sudah memenuhi standar yang ditentukan. Berdasarkan Standar Nilai Prestasi Kerja dan diberlakukannya sistem SKP, kecil kemungkinannya untuk memanipulasi nilai sebagaimana yang sering terjadi di lingkungan kerja yaitu dimana karyawan ingin mendapatkan nilai tinggi atas kinerjanya yang nantinya penilaian ini berpengaruh pada tunjangan yang akan didapatkan. Semakin tinggi nilai yang diperoleh, maka semakin besar tunjangan yang didapat. Maka dari itu perlu dilakukan suatu perubahan mengenai kebiasaan atau budaya bekerja di lingkungan Kemendikbud guna mendongkrak prestasi kerja pegawai dan meminimalisir penurunan angka nilai.

Berdasarkan pemaparan data tersebut masih ada masalah pada kinerja pegawai yang mana masih ada kesalahan-kesalahan kecil yang dilakukan oleh bagian-bagian yang ada di Kementerian Pendidikan dan Kebudayaan Republik Indonesia, sehingga penulis mengambil masalah yang mengenai kinerja pegawai yang perlu didongkrak agar terjadi kenaikan prestasi kerja yang signifikan. Oleh sebab itu penulis mengangkat judul penelitian: "Pengaruh Budaya Organisasi dan Komunikasi Interpersonal terhadap Kinerja Pegawai di Biro Umum Kementerian Pendidikan dan Kebudayaan Republik Indonesia".

\section{KAJIAN PUSTAKA}

\section{Kinerja Pegawai}

Kinerja sering disebut-sebut dalam kegiatan berorganisasi yang mana melihat proses maupun hasil yang dikerjakan oleh pegawai. Adapun pengertian kinerja menurut Dharma (2001, hlm. 33) mengatakan bahwa: "Kinerja karyawan adalah kadar hasil yang dapat ditunjukkan seseorang dalam melaksanakan pekerjaannya" Adapun menurut Hasibuan (2001, hlm. 34) dimana beliau mengungkapkan bahwa "kinerja adalah suatu 
hasil kerja yang dicapai seseorang dalam melaksanakan tugas-tugas yang dibebankan kepadanya yang didasarkan atas kecakapan, pengalaman, dan kesungguhan serta waktu".

Suwatno dan Donni (2011, hlm. 169) mengatakan bahwa "Kinerja atau prestasi kerja merupakan hasil yang dicapai seseorang menurut ukuran yang berlaku, dalam kurun waktu tertentu, berkenaan dengan pekerjaan serta perilaku dan tindakannya".

Kemudian menurut Uno dan Lamatenggo (2012, hlm. 70-71) mengatakan bahwa: "Kinerja adalah skor yang didapat dari gambaran hasil kerja yang dilakukan seseorang atau dengan kata lain unjuk kerja seseorang yang diperoleh melalui instrument pengumpul data tentang kinerja seseorang".

Selanjutnya menurut Sedarmayanti (2009, hlm. 259) mengatakan pengertian kinerja berasal dari terjemahan kata performance, yaitu "Hasil kerja yang dicapai oleh seseorang atau kelompok dalam organisasi, sesuai dengan wewenang dan tanggung jawab masingmasing, dalam rangka upaya mencapai tujuan organisasi bersangkutan secara legal, tidak melanggar hukum dan sesuai dengan moral maupun etika. Adapula menurut Gomes (2003, hlm. 123) menyatakan bahwa: "Kinerja merupakan outcome yang dihasilkan dari suatu fungsi pekerjaan dalam suatu periode waktu tertentu atau pada saat ini”.

Berdasarkan pengertian dan definisi yang dikemukakan oleh para ahli mengenai kinerja pegawai, maka penulis menarik kesimpulan bahwa kinerja pegawai adalah suatu hasil, prestasi, atau nilai yang didapat oleh pegawai atas apa yang dikerjakannya sesuai dengan target dan tujuan organisasi yang dapat diukur pada proses hingga hasil pekerjaannya.

\section{Budaya Organisasi}

Budaya merupakan suatu kebiasaan yang pasti ditemui disemua tempat, tak terkecuali disuatu organisasi. Menurut Luthans (2006, hlm. 137) mendefinisikan bahwa "Budaya organisasi sebagai pola pemikiran dasar yang diajarkan kepada personel baru sebagai cara untuk merasakan, berfikir dan bertindak secara benar dari hari ke hari". Adapula menurut Robbins (2006, hlm. 721) mendefinisikan bahwa "Budaya organisasi adalah suatu sistem makna bersama yang dianut oleh anggota-anggotanya yang membedakan organisasi itu dari organisasi-organisasi lain”. Kemudian menurut Schein (2009) dalam (Onyango, 2014, hlm. 204) mendefinisikan bahwa “...organization culture as collective behavior of people in an organization. "... budaya organisasi sebagai perilaku kolektif dari orang dalam suatu organisasi.

Berdasarkan definisi budaya organisasi menurut para ahli diatas maka penulis menarik kesimpulan bahwa budaya organisasi adalah suatu kebiasaan dalam sebuah organisasi yang dapat membentuk perilaku seseorang menjadi lebih baik.

\section{Komunikasi Interpersonal}

Komunikasi adalah hal yang penting dalam kehidupan sosial, pada dasarnya komunikasi digunakan untuk menyampaikan informasi. Komunikasi dilakukan oleh dua atau lebih orang. Komunikasi adalah proses dengan mana informasi dan arti atau makna ditransfer dari sender kepada receiver (Colquitt, LePine, dan Wesson dalam Wibowo (2013, hlm. 241)).

Menurut Kreitner dan Kinichi, dalam Wibowo (2013, hlm. 241) bahwa komunikasi adalah pertukaran informasi antara sender dan receiver, dan menarik kesimpulan sebagai persepsi tentang makna sesuatu antara individual yang terlibat.

Hovland, Janis \& Kaley dalam Rochajat Harun (2008, hlm. 5) mendefinisikan komunikasi merupakan suatu proses melalui mana seseorang (komunikator) 
menyampaikan stimulus (biasanya dalam bentuk kata-kata) dengan tujuan merubah atau membentuk perilaku orang-orang lainnya (komunikan).

Berdasarkan paparan para ahli diatas maka penulis menyimpulkan bahwa komunikasi adalah proses penyampaian informasi berupa pesan yang dilakukan oleh dua orang atau lebih antara komunikator dengan komunikan yang bermaksud untuk tujuan tertentu. Dengan demikian didalam sebuah komunikasi pasti ada ide atau informasi yang ingin dituangkan oleh komunikator terhadap komunikan.

Komunikasi interpersonal adalah bagian dari komunikasi dimana didalamnya dilakukan oleh dua orang atau lebih yang sangat penting dalam organisasi. Komunikasi interpersonal menurut Stewart (1977) yang dikutip Malcolm R. Parks (2008, hlm. 3) dalam Suranto Aw (2011, hlm. 4) mendefinisikan interpersonal communication in terms of a willingness to share unique aspect of the self. Komunikasi interpersonal menunjukkan adanya kesediaan untuk berbagi aspek-aspek unik dari diri individu. Kemudian Weaver (1978) yang dikutip oleh Malcolm R. Parks (2008, hlm. 3) dalam Suranto Aw (2011, hlm. 3) mendifinisikan interpersonal communication as a dyadic or small group phenomenon which naturally entails communication about the self. Komunikasi interpersonal sebagai fenomena interaksi diadik dua orang atau dalam kelompok kecil yang menunjukkan komunikasi secara alami dan bersahaja tentang diri.

Berdasarkan pemaparan para ahli di atas maka penulis menyimpulman bahwa komunikasi interpersonal adalah sebuah proses pernyampaian atau juga pertukaran informasi diantara dua individu atau lebih yang bertujuan langsung terhadap diri para mereka.

Jadi komunikasi interpersonal terjadi dengan maksud menyampaikan suatu informasi dengan feedback yang dapat diketahui oleh masing-masing individu.

METODE

Adapun metode penelitian yang digunakan penulis di dalam penelitian ini adalah metode deskriptif dan verifikatif. Seperti yang dijelaskan oleh Sugiyono (2009, hlm. 206) bahwa penelitian deskriptif adalah, "penelitian yang digunakan untuk menganalisa data dengan cara mendeskripsikan atau menggambarkan data yang telah terkumpul sebagaimana adanya tanpa membuat kesimpulan yang berlaku umum atau generalisasi".

Menurut Sugiyono (2009, hlm. 73) bahwa: "Sampel merupakan bagian dari jumlah karakteristik yang dimiliki oleh populasi tersebut". Karena jumlah populasi yang terlalu besar dan penelitian tidak mungkin mempelajari semua yang ada pada populasi dikarenakan keterbatasan dana, tenaga, dan waktu maka peneliti menggunakan sampel yang diambil dari populasi tersebut.

Dikarenakan pada Biro Umum Kemendikbud RI ini terdapat 4 Bagian, maka penulis menggunakan teknik sampel Proporsional Random Sampling karena ukuran sampel dialokasikan secara proporsional menurut banyaknya unit sampling dalam strata (ukuran strata) yang diambil sebanyak 80 responden.

Adapun yang akan dianalisis berdasarkan perbedaan antar variabel dengan melakukan uji regresi ganda yang digunakan untuk mempelajari hubungan antara tiga variabel. Koefisien regresi ini berfungsi sebagai alat untuk membuktikan hubungan antara variabel $\mathrm{X}_{1}$ (Budaya Organisasi) dengan Variabel $\mathrm{X}_{2}$ (Komunikasi Interpersonal) serta variabel Y (Kinerja Pegawai). Uji determinasi dipergunakan dengan maksud untuk mengetahui besarnya pengaruh Variabel $X_{1}$ terhadap $Y, X_{2}$ terhadap $Y$ serta $X_{1} X_{2}$ terhadap Y. 


\section{HASIL PENELITIAN DAN PEMBAHASAN}

Dalam penelitian ini diperoleh dari pengolahan instrumen angket yang telah diisi oleh responden. Pengolahan hasil penelitian dibantu dengan aplikasi penghitungan Microsoft Excel 2013 untuk menganalisa seberapa besar pengaruh antara Variabel $\mathrm{X}_{1}$ (Budaya Organisasi) dan $\mathrm{X}_{2}$ (Komunikasi Interpersonal) terhadap Variabel Y (Kinerja Pegawai). Penyebaran angket dilakukan kepada 80 responden yang merupakan sampel di Kementrian Pendidikan dan Kebudayaan Republik Indonesia.

a. Budaya Organisasi

Variabel Budaya Organisasi dalam penelitian ini diukur menggunakan tujuh indikator yaitu Inovasi dan Pengambilan Resiko, Perhatian Terhadap Detail, Orientasi Hasil, Orientasi Orang, Orientasi Tim, Keagresifan, Kemantapan. Ketujuh indikator tersebut diuraikan menjadi 17 pernyataan yang dijadikan ukuran tentang variabel Budaya Organisasi, berdasarkan perhitungan dari 80 orang responden.

Deskripsi variabel Budaya Organisasi diperoleh melalui perhitungan frekuensi dan persentase terhadap perolehan data variabel Budaya Organisasi, sebagaimana tercantum pada lampiran. Berdasarkan perhitungan, diperoleh hasil seperti tampak pada tabel berikut ini:

\begin{tabular}{|l|c|c|c|}
\hline \multicolumn{5}{|c|}{ Tabel 4. 1 } \\
Rekapitulasi Tanggapan Responden Variabel Budaya Organisasi (X1) \\
\hline \multicolumn{1}{|c|}{ Indikator } & Item & Rata-rata & Penafsiran \\
\hline Inovasi Dan Pengambilan Resiko & $1-3$ & 3.57 & KUAT \\
\hline Perhatian Terhadap Detail & $4-6$ & 3.66 & KUAT \\
\hline Orientasi Hasil & $7-8$ & 3.46 & KUAT \\
\hline Orientasi Orang & $9-10$ & 3.57 & KUAT \\
\hline Orientasi Tim & $11-13$ & 3.15 & CUKUP KUAT \\
\hline Keagresifan & $14-15$ & 3.53 & KUAT \\
\hline Kemantapan & $16-17$ & 3.75 & KUAT \\
\hline \multicolumn{2}{|c|}{ Rata-rata } & 3.53 & KUAT \\
\hline
\end{tabular}

Sumber: Skor Hasil Pengolahan Jawaban Responden

Jika dilihat dari tabel 4.1, menunjukkan bahwa rata-rata skor jawaban responden untuk variabel Budaya Organisasi sebesar 3,53. Apabila dihubungkan dengan skala penafsiran pada tabel rekapitulasi skor kriterium, maka angka tersebut berada pada rentang 3,40 - 4,19 atau berada pada kategori kuat.

b. Komunikasi Interpersonal

Variabel Komunikasi Interpersonal dalam penelitian ini diukur menggunakan empat indikator yaitu Instructive, Evaluative, Informative, Influencing, Keempat indikator tersebut diuraikan menjadi 16 pernyataan yang dijadikan ukuran tentang variabel Komunikasi Interpersonal, berdasarkan perhitungan dari 80 orang responden.

Deskripsi variabel Komunikasi Interpersonal diperoleh melalui perhitungan frekuensi dan persentase terhadap perolehan data variabel Komunikasi Interpersonal, sebagaimana tercantum pada lampiran. Berdasarkan perhitungan, diperoleh hasil seperti tampak pada tabel berikut ini: 
Tabel 4. 2

Rekapitulasi Tanggapan Responden Variabel Komunikasi Interpersonal (X2)

\begin{tabular}{|l|c|c|c|}
\hline \multicolumn{1}{|c|}{ Indikator } & Item & Rata-rata & Penafsiran \\
\hline Instructive & $1-4$ & 3.58 & EFEKTIF \\
\hline Evaluative & $5-8$ & 3.76 & EFEKTIF \\
\hline Informative & $9-12$ & 3.58 & EFEKTIF \\
\hline Influencing & $13-16$ & 3.70 & EFEKTIF \\
\hline Rata-rata & & 3.65 & EFEKTIF \\
\hline
\end{tabular}

Sumber: Skor Hasil Pengolahan Jawaban Responden

Jika dilihat dari tabel 4.9, menunjukkan bahwa rata-rata skor jawaban responden untuk variabel Komunikasi Interpersonal sebesar 3,65. Apabila dihubungkan dengan skala penafsiran pada tabel rekapitulasi skor kriterium, maka angka tersebut berada pada rentang 3,40 - 4,19 atau berada pada kategori efektif.

c. Kinerja Pegawai

Variabel Kinerja Pegawai dalam penelitian ini diukur menggunakan delapan indikator yaitu Job Knowledge, Quality of Work, Quantity of Work, Creativeness, Dependability, Initiative, Personal Quality, Cooperation, Kedelapan indikator tersebut diuraikan menjadi 18 pernyataan yang dijadikan ukuran tentang variabel Komunikasi Interpersonal, berdasarkan perhitungan dari 80 orang responden.

Deskripsi variabel Kinerja Pegawai diperoleh melalui perhitungan frekuensi dan persentase terhadap perolehan data variabel Kinerja Pegawai, sebagaimana tercantum pada lampiran. Berdasarkan perhitungan, diperoleh hasil seperti tampak pada tabel berikut ini:

Tabel 4. 3

Rekapitulasi Tanggapan Responden Variabel Kinerja Pegawai (Variabel Y)

\begin{tabular}{|l|c|c|c|}
\hline \multicolumn{1}{|c|}{ Indikator } & Item & Rata-rata & Penafsiran \\
\hline Job Knowledge & $1-2$ & 3.93 & BAIK \\
\hline Quality of Work & $3-5$ & 3.98 & BAIK \\
\hline Quantity of Work & $6-7$ & 4.01 & BAIK \\
\hline Creativeness & $8-9$ & 3.93 & BAIK \\
\hline Dependability & $10-11$ & 4.09 & BAIK \\
\hline Initiative & $12-14$ & 3.81 & BAIK \\
\hline Personal Quality & $15-16$ & 4.18 & BAIK \\
\hline Cooperation & $17-18$ & 4.14 & BAIK \\
\hline \multicolumn{2}{|c|}{ Rata-rata } & 4.01 & BAIK \\
\hline
\end{tabular}

Sumber: Skor Hasil Pengolahan Jawaban Responden

Jika dilihat dari tabel 4.14, menunjukkan bahwa rata-rata skor jawaban responden untuk variabel Kinerja Pegawai sebesar 4.01. Apabila dihubungkan dengan skala penafsiran pada tabel rekapitulasi skor kriterium, maka angka tersebut berada pada rentang $3,40-4,19$ atau berada pada kategori baik.

\section{HIPOTESIS}

Untuk menguji hipotesis tersebut, peneliti menggunakan analisis regresi ganda.Analisis regresi ganda adalah alat untuk meramalkan nilai pengaruh dua variabel 
bebas atau lebih (Budaya Organisasi dan Komunikasi Interpersonal) terhadap satu variabel terikat Kinerja Pegawai dengan tujuan untuk membuktikan ada tidaknya hubungan fungsional atau hubungan kausal antara dua atau lebih variabel bebas terhadap suatu variabel terikat. Persamaan regresi ganda untuk dua variabel bebas yaitu $Y=a+b_{1} X_{1}+$ $b_{2} X_{2}$. Diketahui nilai $\mathrm{F}_{\text {hitung }}$ lebih besar dari nilai $\mathrm{F}_{\text {tabel }}(4111,90>2,3719)$, sehingga pernyataan yang menyebutkan bahwa: "terdapat pengaruh positif signifikan antara Budaya Organisasi dan Komunikasi Interpersonal secara bersama-sama terhadap Kinerja Pegawai di Kemendikbud RI" maka $\mathrm{H}_{1}$ diterima.

Berdasarkan perhitungan pengujian hipotesis diperoleh Fhitung sebesar 4111,90 ,sedangkan Ftabel dengan tingkat kesalahan $\alpha=0,1$ dan $\mathrm{dk}$ reg $\mathrm{b} / \mathrm{a}=1$ dan $\mathrm{dk}$ res $=\mathrm{n}-2=$ 80 sebesar 2,3179, artinya Fhitung $>$ Ftabel yaitu 4111,90 > 2,3179. Maka H0 yang menyatakan bahwa "tidak terdapat pengaruh yang signifikan budaya organisasi dan komunikasi interpersonal terhadap kinerja pegawai di Biro Umum Kementerian Pendidikan dan Kebudayaan Republik Indonesia" ditolak dan tentu saja H1 yang menyatakan bahwa "terdapat pengaruh yang signifikan pemberian budaya organisasi dan komunikasi interpersonal terhadap kinerja pegawai di Biro Umum Kementerian Pendidikan dan Kebudayaan Republik Indonesia" diterima.

Berdasarkan hasil perhitungan data, diperoleh koefisien korelasi simultan antara variabel budaya organisasi dan komunikasi interpersonal terhadap variabel kinerja pegawai sebesar 0,6942, yang kemudian nilai tersebut dikonversikan pada Kriteria Interpretasi Koefisien Korelasi untuk mengetahui derajat hubungan antara variabel budaya organisasi dan komunikasi interpersonal terhadap variabel kinerja pegawai. Setelah dikonversikan ternyata nilai 0,6942 terletak diantara 0,600 sampai dengan 0,799 yaitu termasuk kategori "sangat tinggi". Jadi terdapat hubungan yang tinggi antara variabel budaya organisasi dan komunikasi interpersonal terhadap variabel kinerja pegawai di Biro Umum Kementerian Pendidikan dan Kebudayaan Republik Indonesia.

Berdasarkan hasil perhitungan data, diperoleh nilai koefisien determinasi variabel budaya organisasi dan komunikasi interpersonal terhadap variabel kinerja pegawai $48,20 \%$. Artinya secara simultan variabel kinerja pegawai dipengaruhi oleh variabel budaya organisasi dan komunikasi interpersonal sebesar 48,20\%. Sisanya sebesar 51,80\% dipengaruhi oleh faktor lain di luar dari budaya organisasi dan komunikasi interpersonal. Hasil penelitian ini memberikan beberapa informasi, yaitu: pengaruh budaya organisasi dan komunikasi interpersonal memberikan pengaruh yang positif terhadap kinerja pegawai.

\section{KESIMPULAN}

Berdasarkan hasil penelitian yang dilakukan di Biro Umum Kementerian Pendidikan dan Kebudayaan Republik Indonesia, untuk mengetahui pengaruh budaya organisasi dan komunikasi interpersonal terhadap kinerja pegawai, maka dapat diambil kesimpulan sebagai berikut:

1) Gambaran kuat atau lemahnya budaya organisasi di Biro Umum Kementerian Pendidikan dan Kebudayaan Republik Indonesia yang terdiri dari indikator Inovasi dan Pengambilan Resiko, Perhatian Terhadap Detail, Orientasi Hasil, Orientasi Orang, Orientasi Tim, Keagresifan, Kemantapan. berada pada kategori kuat.

2) Gambaran efektif atau tidak efektifnya komunikasi interpersonal di Biro Umum Kementerian Pendidikan dan Kebudayaan Republik Indonesia yang terdiri dari indikator Instructive, Evaluative, Informative, Influencing berada pada kategori efektif. 
3) Gambaran tinggi atau rendahnya kinerja pegawai di Biro Umum Kementerian Pendidikan dan Kebudayaan Republik Indonesia yang terdiri dari indikator Job Knowledge, Quality of Work, Quantity of Work, Creativeness, Dependability, Initiative, Personal Quality, Cooperation berada pada kategori tinggi.

4) Budaya organisasi berpengaruh positif terhadap kinerja pegawai di Biro Umum Kementerian Pendidikan dan Kebudayaan Republik Indonesia. Hal tersebut menunjukkan bahwa semakin kuat budaya organisasi, akan semakin tinggi kinerja pegawai di Biro Umum Kementerian Pendidikan dan Kebudayaan Republik Indonesia.

5) Komunikasi interpersonal berpengaruh positif terhadap kinerja pegawai di Biro Umum Kementerian Pendidikan dan Kebudayaan Republik Indonesia. Hal tersebut menunjukan bahwa semakin efektif komunikasi interpersonal, akan semakin tinggi kinerja pegawai di Biro Umum Kementerian Pendidikan dan Kebudayaan Republik Indonesia.

6) Budaya organisasi dan komunikasi interpersonal secara bersama-sama mempunyai pengaruh yang positif terhadap kinerja pegawai di Biro Umum Kementerian Pendidikan dan Kebudayaan Republik Indonesia. Sedangkan hasil uji korelasi yang menunjukkan bahwa korelasi budaya organisasi berada pada kategori kuat dan komunikasi interpersonal berada pada kategori efektif dan kinerja pegawai berada pada kategori tinggi. Hal ini menginformasikan bahwa budaya organisasi dan komunikasi interpersonal di Biro Umum Kementerian Pendidikan dan Kebudayaan Republik Indonesia kuat dan efektif sehingga memunculkan tingginya kinerja pegawai.

\section{DAFTAR PUSTAKA}

Aw, S. (2011). Komunikasi Interpersonal. Yogyakarta: Graha Ilmu.

Dharma, A. (2003). Manajemen Supervisi, Petunjuk Praktik bagi Para Supervisor. Jakarta: PT. Raja Grafindo Persada.

Gomes, F. C. (2003). Manajemen Sumber Daya Manusia. Yogyakarta: Andi Offset.

Harun, R. (2008). Komunikasi Organisasi. Bandung: Mandar Maju.

Hasibuan, M. S. (2001). Komunikasi Intrapersonal dan Komunikasi Interpersonal. Yogyakarta: Kansius.

Onyango, W. P. (2014). Effect of Organization Culture on Change Management: A Case of the Vocational Training Centre for the Blind and Deaf Sikre. European Journal of Business and Management, 204.

Luthans, F.(2006). Perilaku Organisasi. Diterjemahkan oleh Vivin Andika Yuwono dkk. Edisi Pertama. Yogyakarta. Andi.

Robbins, Stephen P., (2006). Perilaku Organisasi. Jakarta: Salemba.

Sedarmayanti. (2009). Manajemen Sumber Daya Manusia: Reformasi Birokrasi dan Manajemen Karyawan Negeri Sipil. Bandung: Refika Aditama.

Sugiyono. (2009). Metode Penelitian Administrasi Dilengkapi dengan Metode R\&D. Bandung: Alfabeta. 
Suwatno, \& Donni. (2011). Manajemen Sumber Daya Manusia dalam Organisasi Publik dan Bisnis. Bandung: Alfabeta.

Uno, H. B., \& Lamatenggo, N. (2012). Teori Kinerja dan Pengukurannya. Jakarta: Bumi Aksara.

Wibowo. (2013). Perilaku Dalam Organisasi. Jakarta: Raja Grafindo Persada.

www.bkn.go.id 